\title{
Effects of Cav2.2 inhibitor on hippocampal spatial short- term cognition
}

\author{
Ying Zhou ${ }^{1}$, Kimie Niimi ${ }^{2}$, Weidong $\mathrm{Li}^{1}$, and Eiki Takahashi ${ }^{1,2 *}$ \\ ${ }^{1}$ Bio-X Institutes, Key Laboratory for the Genetics of Developmental and Neuropsychiatric Disorders (Ministry of Education), Shanghai Jiao Tong University, \\ Shanghai, 200240, People's Republic of China \\ ${ }^{2}$ Research Resources Center, RIKEN Brain Science Institute, Saitama, 351-0198, Japan
}

\begin{abstract}
Neuronal voltage gated calcium channels (VGCCs) including Cav2.1 and Cav2.2 channels mediate the presynaptic machinery for vesicular release of neurotransmitters. However, the role of different VGCCs in the neural circuits underlying spatial short-term memory has not been studied. Although it has been reported that spatial cognition requires Cav2.1-regulated signaling in the hippocampus, Cav2.2-regulated function remains unknown. This study examined whether Cav2.2-mediated signaling plays role in spontaneous alternation patterns of Y maze test. Mice received intracerebroventricular injection of Cav2.2 blocker ( $\omega$-conotoxin GVIA, 5 pg/ side) showed impaired spontaneous alternation patterns. Intrahippocampal injection of $\omega$-conotoxin GVIA ( $5 \mathrm{pg} / \mathrm{side})$ induced learning impairment. These results indicate that Cav2.2-mediated signaling is also critical in the hippocampus-dependent spatial cognition.
\end{abstract}

\section{Introduction}

Voltage gated calcium channels (VGCCs) mediate a number of neuronal functions including neurotransmitter release, neuronal excitation, neurite outgrowth, synaptogenesis, neuronal survival, differentiation, plasticity, and regulation of gene expression [1-3]. VGCCs have a molecular complex comprised of several subunits: $\alpha 1$, $\alpha 2-\delta, \beta$, and $\gamma[1]$. The $\alpha 1$ subunit is essential for channel functioning and determines fundamental channel properties [1]. The $\sim 190 \mathrm{kDa}$ poreforming transmembrane $\alpha 1$ subunit ( 2000 amino acids), is organized in four homologous domains (I-IV), comprising six transmembrane a helices (S1-S6) and the pore-forming P loop between S5 and S6 [4]. Genes encoding 10 pore-forming $\alpha 1$ as well as several splice variants have been identified and characterized [4]. Neuronal VGCCs include Cav2.1 and Cav2.2 channels and have predominantly expressions at presynaptic neuronal terminals throughout the central nervous systems [5]. Previous reports have showed that Cav2.1 and Cav2.2 are present at high concentrations in the hippocampus [5], which would be involved in memory formation.

To analyze memory mechanisms in rodents, animals usually learn rules through positive or negative reinforcement during the training session. On the other hand, human cognitive performance is not usually tested with reinforcers such as intense hunger. Y maze test is based on the spontaneous tendency of rodents to enter a novel arm more often than the other arms because of the innate tendency of mice to explore [6]. Thus, the Y maze test would be appropriate for memory formation.

Rolling Nagoya mice carrying a mutation in the $\alpha_{1}$ subunit of the Cav2.1 channel (Cav2.1 $\alpha_{1}$ ) demonstrate severe ataxia after about 2 weeks of age $[7,8]$. In previous study, we showed cognitive alterations in heterozygous Rolling Nagoya ( $\mathrm{rol} /+)$ mice without apparent deficits in the $\mathrm{Y}$ maze test $[9,10]$. It has been thought that $\mathrm{N}$-methyl-D-aspartate (NMDA)-dependent processes are involved in the mechanisms of working memory. The NMDA receptor (NMDAR) antagonists impaired spontaneous alternation of mice in the Y maze test [11-14]. Our previous reports have showed that systemic and intrahippocampal administration of NMDAR antagonist at a lower dose to $\mathrm{rol} /+$ mice would result in hippocampus-dependent cognitive dysfunction [10], suggesting that the importance of hippocampal Cav2.1/NMDAR signaling in spatial short-term memory.

It has been reported that glutamatergic system is one of the neurotransmitter systems regulated by Cav2.1 and Cav2.2 $[15,16]$. The role of different VGCCs in the neural circuits underlying spatial shortterm memory has not been studied. In the present study, to examine the relationship between Cav2.2-mediated synaptic transmission and spatial short-term memory, we conducted the $\mathrm{Y}$ maze test using the mice treated with Cav2.2 inhibitor. The studies presented here demonstrate the importance of hippocampal Cav2.2-regurated signaling in spatial short-term memory.

\section{Materials and methods}

\section{Mice}

All animal procedures were approved by the Animal Experiments Committee of Shanghai Jiao Tong University and RIKEN. The C57BL/6J mice was provided by Charles River Japan (Kanagawa,

Correspondence to: Eiki Takahashi, DVM, PhD. Research Resources Center, RIKEN Brain Science Institute, 2-1 Hirosawa, Wako, Saitama, 351-0198, Japan, Tel: +81-48-467-5871, Fax: +81-48-467-9692; E-mail: etakahashi@brain.riken.jp

Key words: Cav2.2, hippocampus, neuronal circuits, $\omega$-conotoxin GVIA, Y maze test

Received: January 03, 2015; Accepted: January 14, 2015; Published: January 19, 2015 
Japan). The mice were given free access to water and food pellets (CRF1; Oriental Yeast Co. Ltd., Tokyo, Japan) and were housed under a 12/12-h light/dark cycle (lights on from 08:00 to 20:00) at $23 \pm 1^{\circ} \mathrm{C}$ and $55 \pm 5 \%$ humidity. Testing was performed during the light phase of the cycle. We used separate groups of male 2-month-old mice for each of the behavioral tests. All experiments were conducted blind to the treatment condition of the mouse.

\section{Infusion}

For the infusion studies, Cav2.2 blocker, $\omega$-conotoxin GVIA (10, 50, or $100 \mathrm{pg} / \mu \mathrm{L}$, Peptide Institute, Osaka, Japan) were dissolved in saline (vehicle). Under anesthesia and using standard stereotaxic procedures, stainless-steel guide cannulae (22-gauge) were implanted into the lateral ventricle (posterior to bregma, $-0.34 \mathrm{~mm}$; lateral to midline, \pm 0.9 $\mathrm{mm}$; ventral from the dura, $-2.3 \mathrm{~mm})$ or dorsal hippocampus $(-2.0 \mathrm{~mm}$, $\pm 2.0 \mathrm{~mm},-2.0 \mathrm{~mm}$ ). Mice were allowed to recover for at least 1 week following surgery. The mice were briefly anesthetized with isoflurane to facilitate insertion of the injection cannula (26-gauge). Infusions into the lateral ventricle $(0.1 \mu \mathrm{L} /$ side $)$ or hippocampus $(0.1 \mu \mathrm{L} /$ side $)$ are accomplished at a rate of $0.05 \mu \mathrm{L} / \mathrm{min} 30 \mathrm{~min}$ before behavioral testing. The injection cannula was left in place for $2 \mathrm{~min}$ following the infusion. The drug doses were determined according to previous report [17]. Mice that were not treated with drugs received an equivalent volume of vehicle.

\section{Y maze test}

Y maze test was conducted between 10:00 and 16:00 by a trained experimenter who was blind with regard to the mouse strains. The mice were moved into the behavioral testing room at least $2 \mathrm{~h}$ prior to testing. Y-maze apparatus consisted of three compartments $(3 \mathrm{~cm}$ wide $\times 40 \mathrm{~cm}$ long $\times 25 \mathrm{~cm}$ high) radiating out from the center. Before infusion, the mice were placed in one of the compartments and allowed to move freely for $10 \mathrm{~min}$. The light intensity in the experimental room was 35 lux. An arm entry was defined as three legs entering one of the arms, and the sequence of entries was manually recorded. Each mouse performed one trial. An alteration was defined as entry into all three arms in consecutive choices. The percentage of spontaneous alteration was calculated as (actual alteration/maximum alteration) $\times 100$. At the completion of the intrahippocampal injection experiments, fronzen brain sections were examined under a light macroscope. Mice with injection needle placements outside of the boundaries of targeted areas were excluded from behavioral analysis.

\section{Histology}

Histological verification of the cannula locations was performed at the end of behavioral testing. Mice were perfused transcardially with $0.9 \%$ saline, followed by $4 \%$ PFA. After extraction from the skull, the brains were postfixed in $4 \%$ PFA and then transferred to a $30 \%$ sucrose solution until sectioning. Coronal sections ( $40 \mu \mathrm{m}$ thick, taken every $120 \mu \mathrm{m})$ were cut on a cryostat $\left(-16^{\circ} \mathrm{C}\right)$ and mounted on glass microscope slides. After drying, the sections were stained with cresyl violet.

\section{Data analysis}

Data are presented as means \pm standard error on the mean (SEM). Statistical analyses for the behavioral tests were conducted using Excel Statistics 2006 (SSRI, Tokyo, Japan). Data were analyzed using repeated measures ANOVA with Tukey's test.

\section{Results \\ Intracerebroventricular injection effects of $\omega$-conotoxin
GVIA on spatial short-term memory}

We used four groups of male mice $(n=10$ each) given systemic injections of 0 (vehicle), 1,5 , or $10 \mathrm{pg} / \mathrm{side} \omega$-conotoxin GVIA. There were no significant differences among groups in the number of arm entries $[F(3,36)=0.9, P>0.05]$ (Figure 1A). However, the groups significantly differed in the spontaneous alteration $[F(3,36)=133.6$, $P<0.01$ ] (Figure 1B). The mice given 5 or $10 \mathrm{pg} /$ side $\omega$-conotoxin GVIA showed fewer alterations than the mice given vehicle. These results shows that blockade of Cav2.2-mediated signaling impairs short-term memory.

\section{Intrahippocampal injection effects of $\omega$-conotoxin GVIA on spatial short-term memory}

We used four groups of male mice ( $n=10$ each) given intrahippocampal injections of 0 (vehicle), 1,5 , or $10 \mathrm{pg} / \mathrm{side}$ $\omega$-conotoxin GVIA. There were no significant differences among groups in the number of arm entries $[F(3,36)=0.9, P>0.05]$ (Figure $2 \mathrm{~A})$. However, the groups significantly differed in the spontaneous alteration $[F(3,36)=129.5, P<0.01]$ (Figure 2B). The mice given 5 or $10 \mathrm{pg} /$ side $\omega$-conotoxin GVIA showed fewer alterations than the mice given vehicle. Figure 3 shows the representative infusion cannula placement in the dorsal hippocampus. These results shows that blockade of Cav2.2-mediated hippocampus dependent signaling impairs short-term memory.
A

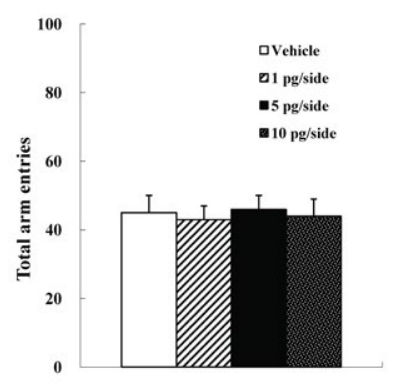

B

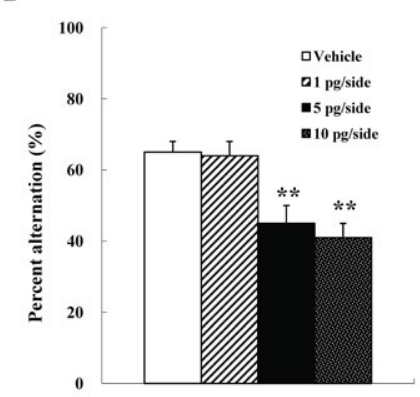

Figure 1. Intracerebroventricular injection effects of $\omega$-conotoxin GVIA on the number of total arm entries (A) and on spontaneous alteration (B) in the $\mathrm{Y}$ maze test. The data are presented as the mean \pm standard error of the mean (SEM). ${ }^{* *} P<0.01$ compared with the appropriate control (Tukey's test).
A

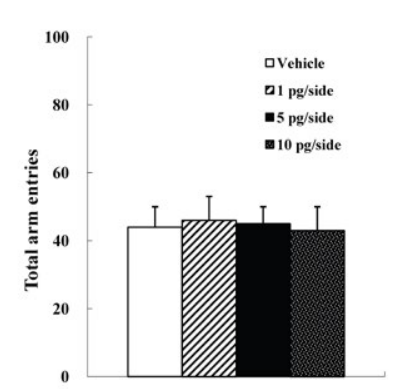

B

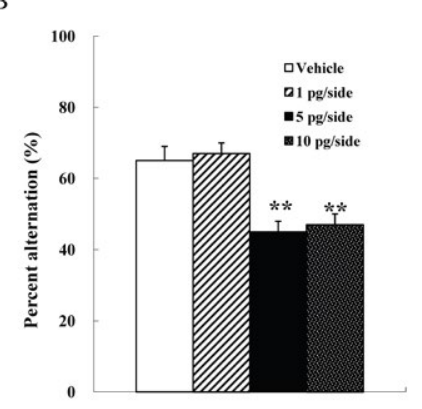

Figure 2. Intrahippocampal injection effects of $\omega$-conotoxin GVIA on the number of tota arm entries (A) and on spontaneous alteration (B) in the Y maze test. The data are presented as the mean \pm standard error of the mean (SEM). ${ }^{* *} P<0.01$ compared with the appropriate control (Tukey's test). 


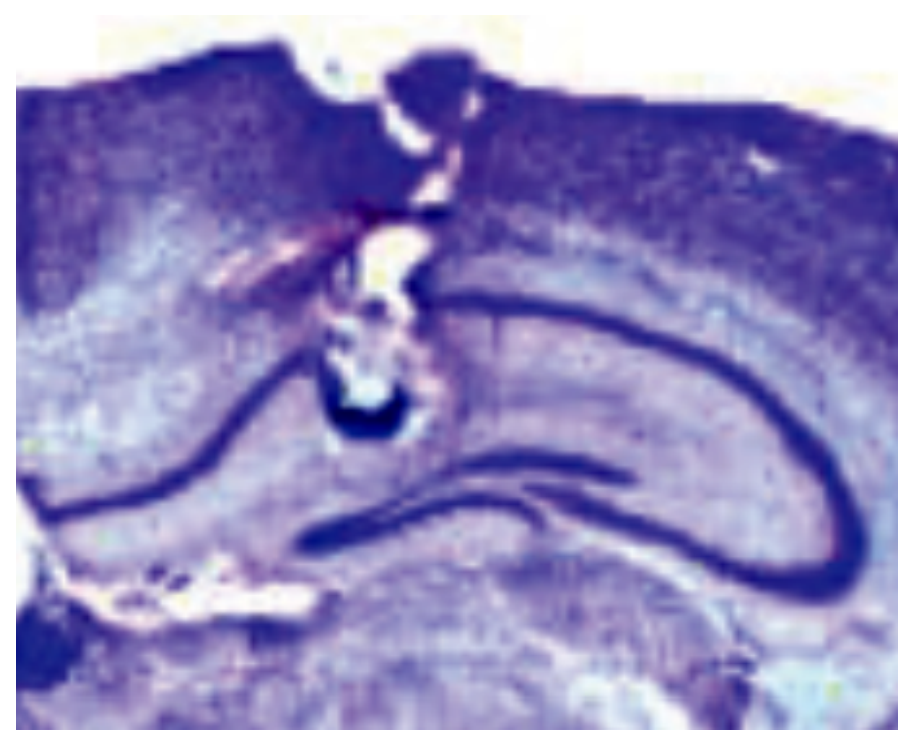

Figure 3. Cannula placement in the dorsal hippocampus. The picture shows the representative cannula placement in the dorsal hippocampus.

\section{Discussion}

Neuronal VGCCs including Cav2.1 and Cav2.2 channels mediates the presynaptic machinery for vesicular release of neurotransmitters. However, the role of different VGCCs in the neural circuits underlying spatial short-term memory has not been studied. In the present study, to examine the relationship between Cav2.2-mediated signaling in the hippocampus and short-term memory formation, we investigated the spontaneous alteration behavior using the wild-type mice received intracerebroventricular or intrahippocampal injection of Cav2.2 blocker ( $\omega$-conotoxin GVIA). It is generally accepted that $\omega$-conotoxin GVIA binding site on the $\alpha_{1}$ subunit of the Cav2.2 channel (Cav2.2 $\left.\alpha_{1}\right)$ has been mapped primarily to the external vestibule of the channel in the domain III pore-forming S5-S6 region $[18,19]$.

We showed that intracerebroventricular injection of $\omega$-conotoxin GVIA blocked the spontaneous alteration behavior, suggesting that the signal cascade activated by Cav 2.2 plays a role in the spatial short-term memory. Because Cav2.2 channels are present at a variety of synapses [5], the systemic injection study is difficult to evaluate from the behavioral performance. Previous studies have demonstrated that the hippocampus is critical for spatial memory formation [20-22]. Intrahippocampal injection in the present study showed that $\omega$-conotoxin GVIA impaired the spontaneous alternation behavior. These results indicate that Cav2.2-regulated signaling in the hippocampus is important in spatial memory formation.

Electrophysiological studies have showed that glutamate releases from presynaptic nerve terminals in hippocampal slices are elicited by $\mathrm{Ca}^{2+}$ influx through Cav2.1 and Cav2.2 [15]. Previous study has also indicated that the glutamatergic systems are both involved in cognitive processes [23]. It has been also reported that systemic and intrahippocampal administration of NMDAR antagonist showed cognitive dysfunction [10]. These results suggest the importance of hippocampal Cav2.2-mediated NMDA receptor signaling in spatial short-term memory. We have also showed that the combination study of different sub-threshold doses of agents and local infusions are useful for inducing the effects of short-term spatial learning and for identifying functional signaling pathways in the specifically neuronal circuits [10]. In the future study, the relationship between Cav2.2mediated glutamatergic transmission in the hippocamous and spatial short-term memory would be investigated using the mice treated with both Cav2.2 inhibitor and NMDA receptor antagonist.

In conclusion, we found that Cav2.2 blocker disrupted the spontaneous alternation behavior in the $\mathrm{Y}$ maze test. Our results suggest that Cav2.2-mediated signaling in the hippocampus has an important role in spatial short-term memory.

\section{Acknowledgments}

This work was supported by China 973 project (2010CB529604) and National Scientific Foundation of China (81271511 and 30900432).

\section{Authors' contributions}

The authors (W.L. and E.T.) designed and supervised the research, and wrote the manuscript. The authors (Y.Z. and K.N.) performed the surgeries and behavioral experiments. All authors read and approved the final version of the manuscript.

\section{References}

1. Catterall WA, Few AP (2008) Calcium channel regulation and presynaptic plasticity Neuron 59: 882-901. [Crossref]

2. Evans RM, Zamponi GW (2006) Presynaptic Ca2+ channels--integration centers for neuronal signaling pathways. Trends Neurosci 29: 617-624. [Crossref]

3. Jarvis SE, Zamponi GW (2007) Trafficking and regulation of neuronal voltage-gated calcium channels. Curr Opin Cell Biol 19: 474-482. [Crossref]

4. Takahashi E (2012) Cav2.1 channelopathy and mouse genetic approaches to investigate function and dysfunction of Cav2.1 channel. In: M. Yamaguchi, ed. 2012. Calcium Signaling. New York. Nova Science Publishers, Inc. Chapter 7. p149-158

5. Tanaka O, Sakagami H, Kondo H (1995) Localization of mRNAs of voltage-dependen $\mathrm{Ca}(2+)$-channels: four subtypes of alpha 1 - and beta-subunits in developing and mature rat brain. Brain Res Mol Brain Res 30: 1-16. [Crossref]

6. Granon S, Save E, Buhot MC, Poucet B (1996) Effortful information processing in a spontaneous spatial situation by rats with medial prefrontal lesions. Behav Brain Res 78: 147-154. [Crossref]

7. Mori Y, Wakamori M, Oda S, Fletcher CF, Sekiguchi N, et al. (2000) Reduced voltage sensitivity of activation of $\mathrm{P} / \mathrm{Q}$-type $\mathrm{Ca} 2+$ channels is associated with the ataxic mouse mutation rolling Nagoya (tg(rol)). J Neurosci 20: 5654-5662. [Crossref]

8. Oda S (1973) [The observation of rolling mouse Nagoya (rol), a new neurological mutant, and its maintenance (author's transl)]. Jikken Dobutsu 22: 281-288. [Crossref]

9. Takahashi E, Niimi K (2009) Spatial learning deficit in aged heterozygous Cav2.1 channel mutant mice, rolling mouse Nagoya. Exp Gerontol 44: 274-279. [Crossref]

10. Takahashi E, Niimi K, Itakura C (2010) Impairment of spatial short-term memory following acute administration of the NMDA receptor antagonist in heterozygous rolling Nagoya mice carrying the Ca V 2.1 alphal mutation. Behav Brain Res 213: 121-125. [Crossref]

11. Bischoff C, Tiedtke PI (1992) Competitive and non-competitive NMDA receptor antagonists in spatial learning tasks. Eur J Pharmacol 213: 269-273. [Crossref]

12. Maurice T, Su TP, Parish DW, Nabeshima T, Privat A (1994) PRE-084, a sigma selective PCP derivative, attenuates MK-801-induced impairment of learning in mice. Pharmacol Biochem Behav 49: 859-869. [Crossref]

13. Niimi K, Takahashi E, Itakura C (2008) Improved short-term memory and increased expression of NR2B observed in senescence-accelerated mouse (SAM) P6. Exp Gerontol 43: 847-852. [Crossref]

14. Parada-Turska J, Turski WA (1990) Excitatory amino acid antagonists and memory: effect of drugs acting at N-methyl-D-aspartate receptors in learning and memory tasks. Neuropharmacology 29: 1111-1116. [Crossref]

15. Kimura M, Katayama K, Nishizawa Y (1999) Role of glutamate receptors and voltagedependent calcium channels in glutamate toxicity in energy-compromised cortical neurons. Jpn J Pharmacol 80: 351-358. [Crossref] 
16. Lee I, Hunsaker MR, Kesner RP (2005) The role of hippocampal subregions in detecting spatial novelty. Behav Neurosci 119: 145-153. [Crossref]

17. Ogura H, Furuya Y, Teramoto T, Niidome T, Nishizawa Y, et al. (1998) Peptide N- and $\mathrm{P} / \mathrm{Q}-$ type $\mathrm{Ca} 2+$ blockers inhibit stimulant-induced hyperactivity in mice. Peptides 19 ; 1017-1022. [Crossref]

18. Lewis RJ, Dutertre S, Vetter I, Christie MJ (2012) Conus venom peptide pharmacology. Pharmacol Rev 64: 259-298. [Crossref]

19. Sousa SR1, Vetter I, Lewis RJ (2013) Venom peptides as a rich source of cav2.2 channel blockers. Toxins (Basel) 5: 286-314. [Crossref]
20. Gilbert PE, Kesner RP (2004) Memory for objects and their locations: the role of the hippocampus in retention of object-place associations. Neurobiol Learn Mem 81: 3945. [Crossref]

21. Mumby DG, Gaskin S, Glenn MJ, Schramek TE, Lehmann H (2002) Hippocampa damage and exploratory preferences in rats: memory for objects, places, and contexts. Learn Mem 9: 49-57. [Crossref]

22. Murai T, Okuda S, Tanaka T, Ohta H (2007) Characteristics of object location memory in mice: Behavioral and pharmacological studies. Physiol Behav 90: 116-124. [Crossref]

23. Niimi K, Han Y, Zhou Y, Yoshimoto T, Dai F, et al. (2014) Blockade of Cav2.1mediated NMDA receptor signaling disrupts conditioned fear extinction. Behav Brain Res 259: 45-49. [Crossref]

Copyright: (C2015 Zhou Y. This is an open-access article distributed under the terms of the Creative Commons Attribution License, which permits unrestricted use, distribution, and reproduction in any medium, provided the original author and source are credited. 